\title{
Asparagine-linked glycosylation modifies voltage-dependent gating properties of $\mathrm{Ca}_{\mathrm{v}}$ 3.1-T-type $\mathrm{Ca}^{2+}$ channel
}

\author{
Yangong Liu ${ }^{1,2} \cdot$ Pu Wang ${ }^{1,2} \cdot$ Fangfang Ma ${ }^{1,2} \cdot$ Mingqi Zheng ${ }^{1} \cdot$ Gang Liu $^{1} \cdot$ Shinichiro Kume ${ }^{2} \cdot$ Tatsuki Kurokawa $^{2}$. \\ Katsushige Ono ${ }^{2} \mathbb{}$
}

Received: 16 August 2018 / Accepted: 5 December 2018 / Published online: 1 January 2019

(C) The Physiological Society of Japan and Springer Japan KK, part of Springer Nature 2019

\begin{abstract}
T-type channels are low-voltage-activated channels that play a role in the cardiovascular system particularly for pacemaker activity. Glycosylation is one of the most prevalent post-translational modifications in protein. Among various glycosylation types, the most common one is asparagine-linked ( $N$-linked) glycosylation. The aim of this study was to elucidate the roles of $N$-linked glycosylation for the gating properties of the $\mathrm{Ca}_{\mathrm{V}} 3.1-\mathrm{T}$-type $\mathrm{Ca}^{2+}$ channel. $N$-linked glycosylation synthesis inhibitor tunicamycin causes a reduction of $\mathrm{Ca}_{\mathrm{V}} 3.1-\mathrm{T}$-type $\mathrm{Ca}^{2+}$ channel current $\left(\mathrm{Ca}_{\mathrm{V}} 3.1-I_{\text {Ca.T }}\right)$ when applied for $12 \mathrm{~h}$ or longer. Tunicamycin $(24 \mathrm{~h})$ significantly shifted the activation curve to the depolarization potentials, whereas the steady-state inactivation curve was unaffected. Use-dependent inactivation of $\mathrm{Ca}_{\mathrm{V}} 3.1-I_{\text {Ca.T }}$ was accelerated, and recovery from inactivation was prolonged by tunicamycin $(24 \mathrm{~h})$. $\mathrm{Ca}_{\mathrm{V}} 3 \cdot 1-\mathrm{I}_{\mathrm{Ca} . \mathrm{T}}$ was insensitive to a glycosidase PNGase $\mathrm{F}$ when the channels were expressed on the plasma membrane. These findings suggest that $N$-glycosylation contributes not only to the cell surface expression of the $\mathrm{Ca}_{\mathrm{v}}$ 3.1-T-type $\mathrm{Ca}^{2+}$ channel but to the regulation of the gating properties of the channel when the channel proteins were processed during the folding and trafficking steps in the cell.
\end{abstract}

Keywords Glycosylation $\cdot$ T-type $\mathrm{Ca}^{2+}$ channel $\cdot \mathrm{Ca}_{\mathrm{V}} 3.1 \cdot \alpha 1 \mathrm{G}$ channel $\cdot$ Tunicamycin

\section{Introduction}

T-type calcium channels, known as low-voltage-activated calcium channel or transient-type calcium channel, are predominantly expressed in the atria and nodal cells in the heart. In particular, T-type $\mathrm{Ca}^{2+}$ channels contribute to the generation of action potentials in nodal cells at the phase of slow diastolic depolarization. Genetic analysis demonstrated that two types of T-type $\mathrm{Ca}^{2+}$ channel isoforms, $\mathrm{Ca}_{\mathrm{v}} 3.1$ and $\mathrm{Ca}_{\mathrm{V}} 3.2$, are widely expressed in the heart [1-3]. Studies of genetically modified mice with targeted inactivation of the T-type $\mathrm{Ca}^{2+}$ channel suggest that $\mathrm{Ca}_{\mathrm{V}} 3.1$-T-type $\mathrm{Ca}^{2+}$ channel underlies the functional T-type $\mathrm{Ca}^{2+}$ channel in the heart for the generation of pacemaker rhythm $[1,2,4]$ particularly

Katsushige Ono

ono@oita-u.ac.jp

1 Department of Cardiology, The First Hospital of Hebei Medical University, 89 Donggang Road, Shijiazhuang, Hebei Province 050031, People's Republic of China

2 Department of Pathophysiology, Oita University School of Medicine, Yufu, Oita 879-5593, Japan with adult animals [1]. Regarding the automaticity in the pacemaker cells, failure to generate the nodal electrical impulse underlies congenital or acquired bradycardia and bradycardia-associated conditions, such as atrial fibrillation [5]. Sick sinus syndrome is the term used to describe the inability of the sinus node to generate heart rhythms that meet the physiologic needs of an individual. Sinus node dysfunction occurs as a result of disorders in automaticity, conduction, or both. Although several causes of the acquired sick sinus dysfunction including idiopathic degenerative disease have been postulated, molecular mechanisms for the pacemaker dysfunction are mostly unknown.

Ion channels are subject to complex regulation by a wide range of cytosolic modulators [5, 6]. Ion channels are also subject to multiple post-transcription regulatory mechanisms, including glycosylation, formation of disulfide bonds, enzyme digestion, phosphorylation, and ubiquitination [7-9]. Asparagine (Asn, $N$ )-linked glycosylation $(\mathrm{N}$-glycosylation) has been investigated to affect the structural folding, membrane targeting, expression level, stability, and voltage-dependent properties of many ion channels including the T-type $\mathrm{Ca}^{2+}$ channels. For instance, reduction 
or elimination of $\mathrm{N}$-glycosylation of the $\mathrm{Ca}_{\mathrm{v}} 3.2-\mathrm{T}$-type $\mathrm{Ca}^{2+}$ channel was reported to decrease channel activity and expression with altered channel kinetics [10]. In this study, we analyzed an impact of the reduction of $\mathrm{N}$-glycosylation of the $\mathrm{Ca}_{\mathrm{v}}$ 3.1-T-type $\mathrm{Ca}^{2+}$ channel, the other isoform of the channel in the heart. We employed patch-clamp techniques to study kinetics of the channel in heterologous expression system with human embryonic kidney cells (HEK293) cells. Tunicamycin has been widely used as a standard method in the study of glycoprotein synthesis in various biological systems $[9,10]$. Tunicamycin inhibits $N$-acetylglucosamine-1-phosphate transferase (GlcNAc phosphotransferase) and inhibits the formation of $\mathrm{N}$-glycosidic linkages in glycoprotein synthesis $[9,10]$. Inhibition of $N$-linked glycosylation synthesis using tunicamycin causes a reduction of $\mathrm{Ca}_{\mathrm{V}} 3.1-\mathrm{T}$-type $\mathrm{Ca}^{2+}$ channel current $\left(\mathrm{Ca}_{\mathrm{V}} 3 \cdot 1-\mathrm{I}_{\mathrm{Ca} . \mathrm{T}}\right)$ density when applied for $12 \mathrm{~h}$ or longer, as a long-term effect, although tunicamycin does not affect $\mathrm{Ca}_{\mathrm{V}} 3 \cdot 1-\mathrm{I}_{\text {Ca.T }}$ as an acute effect. Tunicamycin significantly shifted the activation curve toward the depolarization potentials, whereas the steady-state inactivation curve was unaffected, when tunicamycin was applied for $24 \mathrm{~h}$. On the other hand, $\mathrm{Ca}_{\mathrm{V}} 3.1-\mathrm{I}_{\mathrm{Ca} . \mathrm{T}}$ was insensitive to a glycosidase PNGase F when the glycosylated channels were expressed on the plasma membrane. These findings suggest that $\mathrm{N}$-glycosylation contributes not only to the cell surface expression of the $\mathrm{Ca}_{\mathrm{V}}$ 3.1-T-type $\mathrm{Ca}^{2+}$ channel but also to the regulation of the gating properties of the channel when the channel proteins were processed during the folding and trafficking steps in the cell. It is also suggested that deglycosylation of the $\mathrm{Ca}_{\mathrm{v}} 3.1-\mathrm{T}$-type $\mathrm{Ca}^{2+}$ channel can be a potential method to reduce heart rate or to treat tachycardia-mediated arrhythmias in the heart.

\section{Materials and methods}

\section{Expression of $\mathrm{Ca}_{\mathrm{v}} 3.1$ channel in mammalian cells and cell-culture condition}

The Ca $\mathrm{V}_{\mathrm{V}}$ 3.1-T-type $\mathrm{Ca}^{2+}$ channel isoform ( $\alpha 1 \mathrm{G}$ submit) derived from human was stably expressed in human embryonic kidney (HEK)-293 cells with no auxiliary subunits. HEK-293 cells were maintained in DMEM, supplemented with $10 \%$ fetal bovine serum, $100 \mu / \mathrm{ml}$ penicillin, and $100 \mathrm{mg} / \mathrm{l}$ streptomycin, in an atmosphere of $95 \%$ $\mathrm{O}_{2}$ and $5 \% \mathrm{CO}_{2}$ at $37^{\circ} \mathrm{C}$. This medium was supplemented with $350 \mathrm{mg} / \mathrm{l} \mathrm{G} 418$ for selection of recombinant HEK293 cells. For the study on the time-dependent effects of tunicamycin, the HEK-Ca 3.1 cells were incubated with or without $10^{-2} \mathrm{~g} / \mathrm{l}$ tunicamycin (Wako Chemicals, Japan) for $1 \mathrm{~h}, 6 \mathrm{~h}, 12 \mathrm{~h}$, or $24 \mathrm{~h}$ prior to the electrophysiological measurements. For the study on chemical cleavage for removal of glycosylation of HEK-Ca 3.1 cells, a non-specific glycosidase Peptide- $N$-Glycosidase F (PNGase F) was applied in the cell-culture medium for $2 \mathrm{~h}$ prior to the electrophysiological measurements according to manufacture instruction. For the study on the concentration dependent effects of tunicamycin, HEK-Ca 3.1 cells were incubated with $10^{-6} \mathrm{~g} / 1,10^{-5} \mathrm{~g} / 1,10^{-4} \mathrm{~g} / 1,10^{-3} \mathrm{~g} / \mathrm{l}$, or $10^{-2} \mathrm{~g} / \mathrm{l}$ tunicamycin for $24 \mathrm{~h}$ before electrophysiological measurements.

\section{Electrophysiology}

Whole-cell current-clamp and voltage-clamp experiments were performed using EPC-9 amplifier (HEKA Elektronik, Germany) at room temperature $\left(20-24{ }^{\circ} \mathrm{C}\right)$. Acquisition and analysis were performed using Patchmaster software (HEKA). The bath solution contained (in millimolar): TEA$\mathrm{Cl} 120, \mathrm{CsCl} 6$, 4-AP 5, $\mathrm{MgCl}_{2}$ 0.5, DIDS 0.5, HEPES 10, $\mathrm{CaCl}_{2} 1.8$, glucose 10 (pH 7.4 with TEA-OH). Patch pipettes were filled with pipette solution containing (in millimolar) CsCl 130, Mg-ATP 2, EGTA 5, HEPES 10 (pH 7.2 with $\mathrm{CsOH}$ ) and had a resistance of 2-4 M $\Omega$. The T-type calcium channel current $\left(I_{\mathrm{Ca} . \mathrm{T}}\right)$ was recorded in response to a series of test steps to depolarized potentials ranging from -100 to $+50 \mathrm{mV}$ for $250 \mathrm{~ms}$ from a holding potential of $-100 \mathrm{mV}$, with 2-s sweep interval and 10-kHz sampling frequency. The activation curves were fitted with the following modified Boltzmann equation: $G / G_{\max }=\left[1+\exp \left(V_{1 / 2 \text {-act }}-V\right) / k\right]^{-1}$, where $G_{\max }$ is the maximum conductance, $V_{1 / 2 \text {-act }}$ is the half-activation potential and $\mathrm{k}$ is the slope factor. $I_{\text {Ca.T }}$ was further characterized by its voltage-dependent inactivation properties. HEK-Cav3.1 cells were held at a range of conditioning potentials (from -100 to $-20 \mathrm{mV}$ ) for $2 \mathrm{~s}$ and then stepped to a test potential of $-20 \mathrm{mV}$. The steady-state inactivation curve was fitted with an equation: $I / I_{\max }=[1+\exp$ $\left.\left(V-V_{1 / 2 \text {-SSI }}\right) / k\right]^{-1}$, where $V_{1 / 2 \text {-SSI }}$ is the half-inactivation potential. For a measurement of the use-dependent reduction of $I_{\mathrm{Ca}, \mathrm{T}}$, repetitive stimulation (a train pulse at $-20 \mathrm{mV}$ for $200-\mathrm{ms}$ duration) of $0.4-\mathrm{Hz}, 2.5-\mathrm{Hz}$, and $4-\mathrm{Hz}$ repetitive voltage pulses were given to HEK-Cav3.1 cells from the holding potentials of $-100 \mathrm{mV}$. $I_{\text {С.T }}$ recorded from the second test pulses or later $\left(I_{\mathrm{x}}\right)$ were normalized to the current recorded from the first pulse ( $I_{1}$ assigned as 1.0), yielding the ratio of $I_{x} / I_{1}$. To analyze the recovery phase of the channel inactivation, HEK-Cav3.1 cells were held at $-100 \mathrm{mV}$ and a pair-pulse at $-20 \mathrm{mV}$ with variable interval time was applied. The interval time between the two pulses (interstimulus interval) was adjusted from $2 \mathrm{~ms}$ to $2000 \mathrm{~ms}$. Peak $I_{\text {Ca.T }}$ recorded by the second pulse was normalized by $I_{\text {Ca.T }}$ at the first pulse. Normalized $I_{\text {Сa.T }}$ was plotted against the function of interval time and fitted by bi-exponential equation to obtain the recovery time constant, $\tau$-fast and $\tau$-slow. 


\section{Statistical analysis}

Data were acquired using computer software (Pachmaster, HEKA), and all curve fittings and figures were made on Sigma Plot ver. 10 (Systat Software Inc, USA). All results are presented as mean \pm SEM, with the number of observations indicated by $n$. Values were analyzed by Student's $t$ test or Holm-Sidak method when multiple comparisons were needed. Differences were considered significant at $p<0.05$.

\section{Results}

\section{Time-dependent effects of tunicamycin on $\mathrm{Ca}_{\mathrm{v}} 3.1-\mathrm{I}_{\mathrm{Ca} . \mathrm{T}}$}

Effects of tunicamycin on the HEK-Ca 3.1 cells were assessed when applied in the culture medium for 1 to $24 \mathrm{~h}$
(Fig. 1). Although tunicamycin was without effects on $\mathrm{Ca}_{\mathrm{v}} 3 \cdot 1-\mathrm{I}_{\text {Ca.T }}$ applied in the culture medium for $1 \mathrm{~h}$ or $6 \mathrm{~h}$, $\mathrm{Ca}_{\mathrm{V}} 3.1-I_{\text {Ca.T }}$ was significantly decreased when applied for $12 \mathrm{~h}$ or longer. Importantly, reduction ratio of $\mathrm{Ca}_{\mathrm{V}} 3.1-I_{\text {Ca.T }}$ by tunicamycin was time dependent; $\mathrm{Ca}_{\mathrm{V}} 3 \cdot 1-I_{\text {Ca.T }}$ with the action of tunicamycin for $24 \mathrm{~h}$ was significantly smaller than that with tunicamycin for $12 \mathrm{~h}$ (Fig. 1). The ratio of the maximal $I_{\text {Сa.T }}$ density in tunicamycin group to vehicle group $\left(I_{\max (\text { Tuni })} / I_{\max (\mathrm{Veh})}\right)$, and the ratio of the maximal conductance in tunicamycin group to vehicle group $\left(G_{\max (\text { Tuni })} / G_{\max (\mathrm{Veh})}\right)$ also indicate the time-dependent reduction caused by tunicamycin treatment (Fig. 1). These ratios were less than $50 \%$ in the $12 \mathrm{~h}$ and were even more decreased in the $24 \mathrm{~h}$. Given that tunicamycin inhibits the first step of glycosylation, it may need a certain time to exert an inhibitory effect on $\mathrm{Ca}_{\mathrm{V}} 3 \cdot 1-I_{\text {Ca.T }}$, which is consistent with a notion that the reduction of $\mathrm{Ca}_{\mathrm{v}} 3 \cdot 1-I_{\text {Ca.T }}$ was caused by the inhibition of $\mathrm{N}$-glycosylation synthesis
Fig. 1 Time-dependent effects of glycosylation inhibition with tunicamycin on $\mathrm{Ca}_{\mathrm{V}} 3.1-I_{\text {Ca.T. }}$. Representative current traces with vehicle and tunicamycin treatment, and group data for current $(I)$-voltage $(V)$ relationship. HEK-Ca $\mathrm{a}_{\mathrm{v}} 3.1$ cells were incubated with vehicle or tunicamycin $\left(10^{-2} \mathrm{~g} / \mathrm{l}\right)$ for $1 \mathrm{~h}(\mathbf{a})$, $6 \mathrm{~h}(\mathbf{b}), 12 \mathrm{~h}(\mathbf{c})$, or $24 \mathrm{~h}(\mathbf{d})$. Changes of the maximum $I_{\text {Ca.T }}$ $\left(I_{\max }\right)$ and the maximum conductance $\left(G_{\max }\right)$ by glycosylation inhibition with tunicamycin are shown as group data (e, f).

The ordinate indicates the ratio of the maximum inward current (e) and the maximum conductance (f) with tunicamycin normalized to that with vehicle at the same incubation period.

The number of cells is indicated in parentheses. Values represent the mean \pm SE. $* p<0.01$ vs. the ratio at $1 \mathrm{~h} . \# p=0.06$ vs. the ratio at $12 \mathrm{~h}$. $\dagger p=0.12 \mathrm{vs}$. the ratio at $12 \mathrm{~h}$
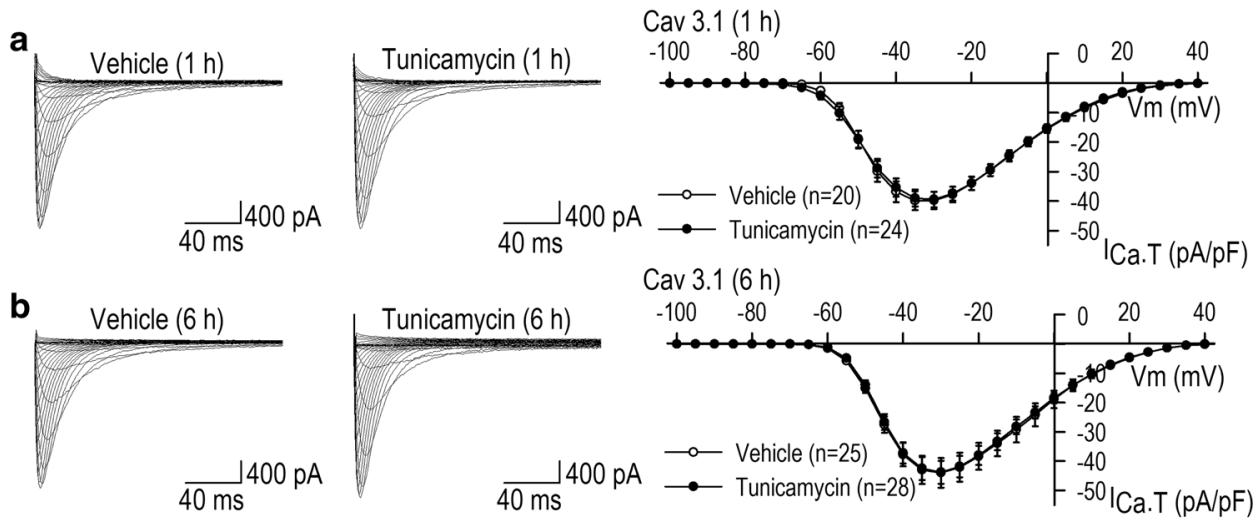

c
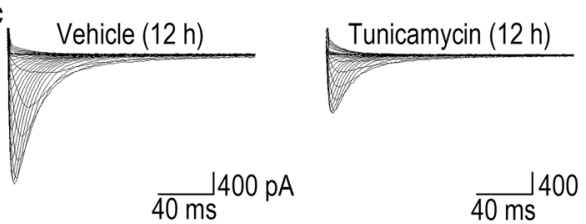

Cav 3.1 (12 h)

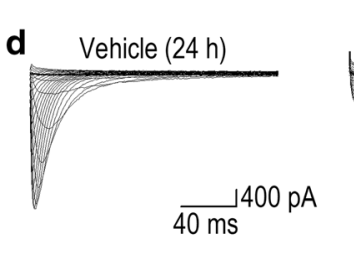

e

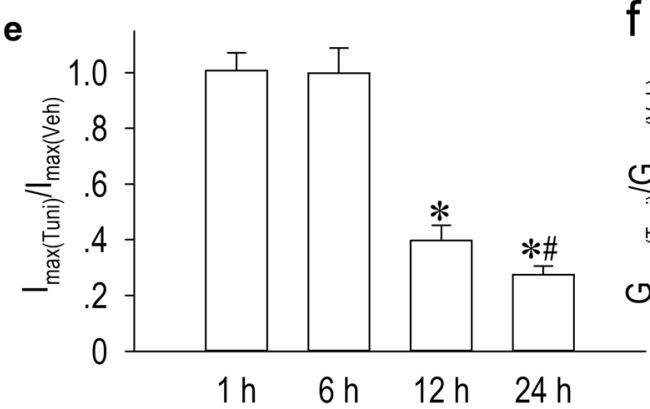

$\mathrm{f}$

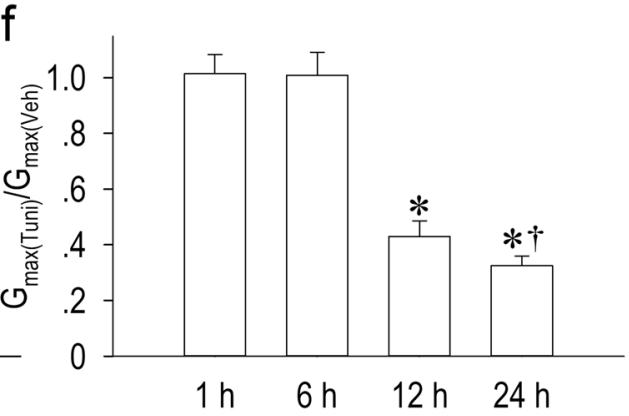


rather than a direct effect on the $\mathrm{Ca}_{\mathrm{v}} 3.1$ channel on the cell surface membrane.

\section{Kinetic modulation by inhibition of $\mathrm{N}$-glycosylation}

Without glycosylation, some proteins are not folded correctly or not stable. In view of potentially functional effects of $N$-glycosylation on the $\mathrm{Ca}_{\mathrm{v}} 3.1-\mathrm{T}$-type $\mathrm{Ca}^{2+}$ channel, we have analyzed a long-term effect of tunicamycin on the activation and the inactivation properties of the channel. We constructed the activation curve and the steady-state inactivation curve of $\mathrm{Ca}_{\mathrm{V}} 3 \cdot 1-I_{\mathrm{Ca} . T}$; the activation curve was shifted toward the depolarization direction when $\mathrm{HEK}-\mathrm{Ca}_{\mathrm{v}} 3.1$ cells were incubated with tunicamycin for $12 \mathrm{~h}$, while the inactivation curves was unaffected at the same condition (Fig. 2c). Importantly, the activation curve was even more shifted toward the depolarization direction when $\mathrm{HEK}-\mathrm{Ca}_{\mathrm{v}} 3.1$ cells were incubated with tunicamycin for $24 \mathrm{~h}$ (Fig. 2d). Analysis and comparison of the potentials for the half-maximum activation ( $V_{1 / 2}$-activation) and the half-maximum inactivation ( $V_{1 / 2}$-inactivation) demonstrated a shift of activation curves but not inactivation curves toward the hyperpolarization direction by the treatment of the channel with tunicamycin (Fig. 2). Long-term (24 h) application of tunicamycin decreased $\mathrm{Ca}_{\mathrm{V}} 3.1-I_{\mathrm{Ca} . \mathrm{T}}$ in a dose-dependent manner with $\mathrm{IC}_{50}$ of $2.01 \times 10^{-3} \mathrm{~g} / 1$ or $10^{-2.697} \mathrm{~g} / \mathrm{l}$ (Fig. 3). Tunicamycin at $10^{-3} \mathrm{~g} / 1$ concentration significantly decreased the maximum inward current by $37 \%$ (Fig. 3b). Consistently, $\mathrm{V}_{1 / 2}$-activation was appreciably shifted toward the depolarization direction by tunicamycin with the concentration of $10^{-3} \mathrm{~g} / \mathrm{l}$, and the shift became significant with the concentration of $10^{-2} \mathrm{~g} / \mathrm{l}$ (Fig. 4). To evaluate the tonic and
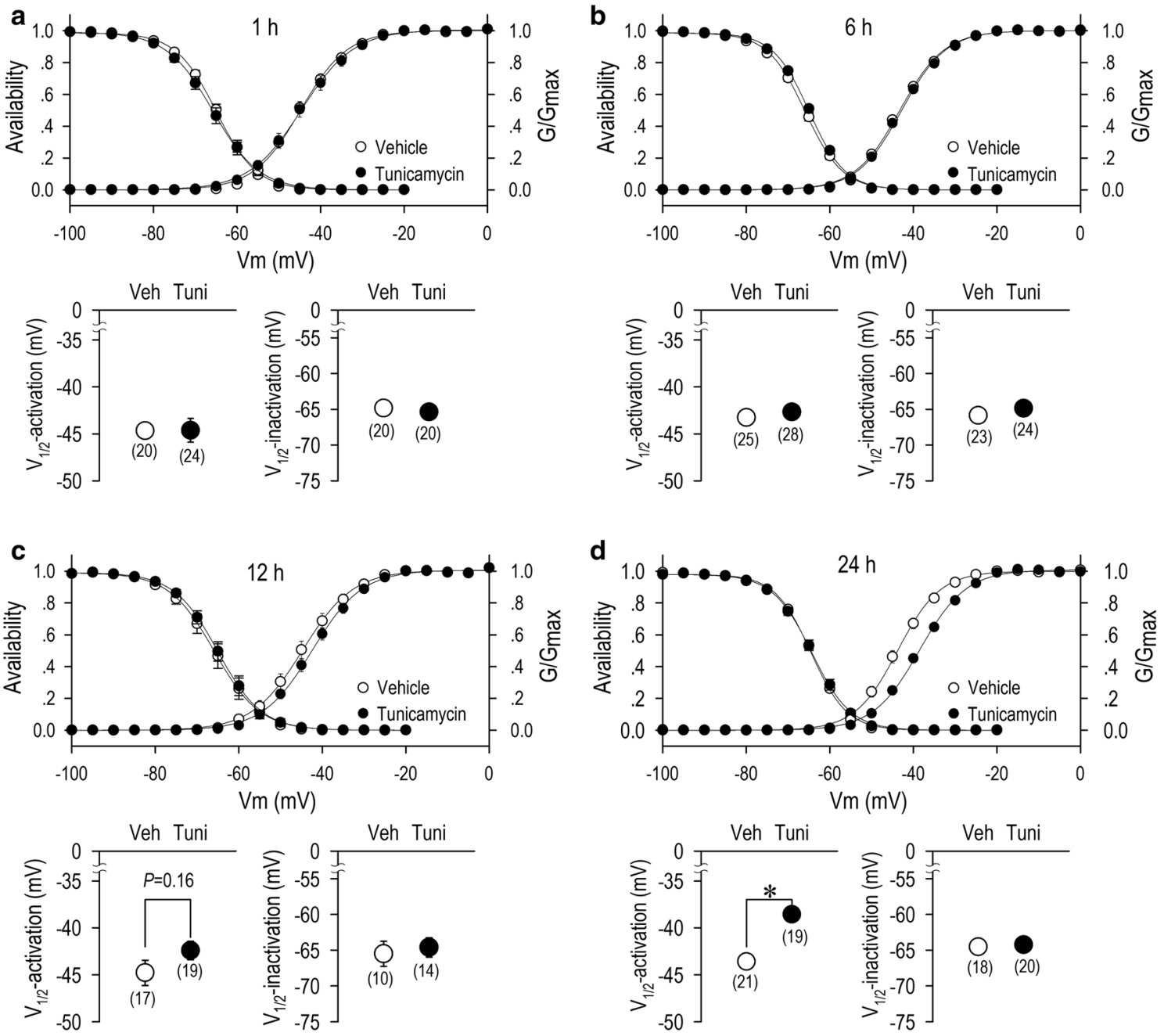

Fig. 2 Changes of the activation $\left(G / G_{\max }\right)$ and the steady-state inactivation (availability) curves by glycosylation inhibition with tunicamycin, and their parameters of half-activation potentials ( $V_{1 / 2}$-activation) and half-inactivation potentials $\left(V_{1 / 2}\right.$-inactivation). Both curves were

obtained by Boltzmann fittings with data when cells were incubated with vehicle or tunicamycin $\left(10^{-2} \mathrm{~g} / \mathrm{l}\right)$ for $1 \mathrm{~h}(\mathbf{a}), 6 \mathrm{~h}(\mathbf{b}), 12 \mathrm{~h}(\mathbf{c})$, or $24 \mathrm{~h}(\mathbf{d})$. The number of cells is indicated in parentheses. Values represent the mean \pm SE. $* p<0.01$ vs. vehicle 


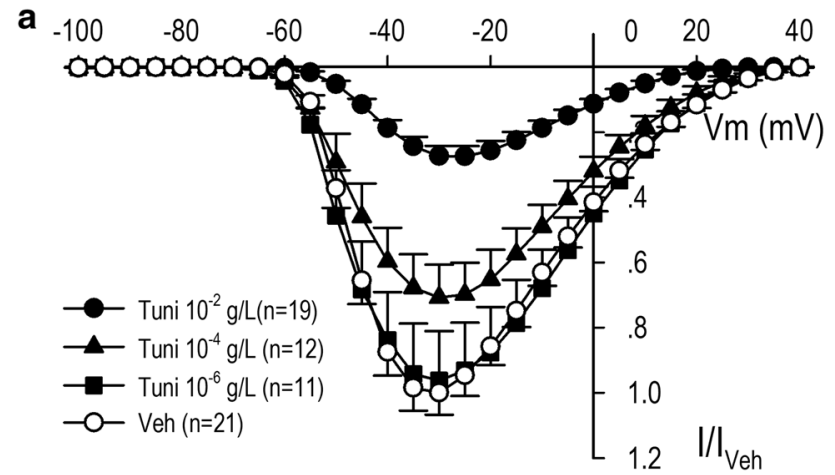

b

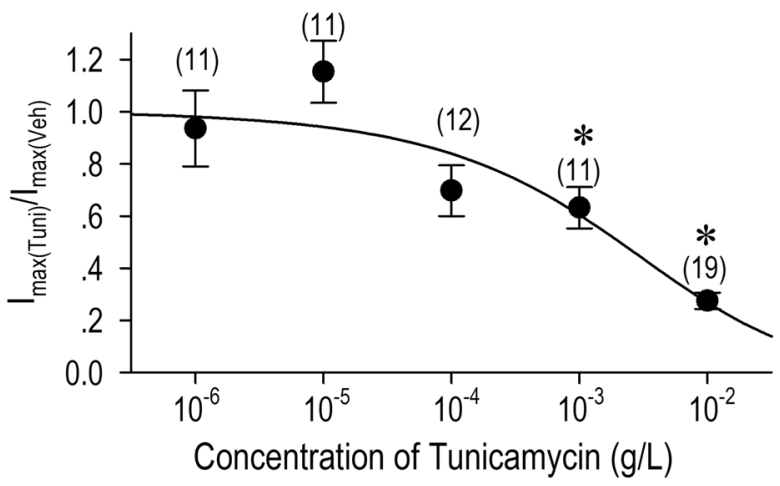

Fig. 3 Concentration-dependent effects of tunicamycin on $\mathrm{Ca}_{\mathrm{V}} 3.1-I_{\mathrm{Ca} . \mathrm{T}}$. HEK-Ca 3.1 cells were incubated for $24 \mathrm{~h}$ with vehicle or tunicamycin at the concentration of $10^{-6} \mathrm{~g} / 1,10^{-5} \mathrm{~g} / 1,10^{-4}$ $\mathrm{g} / \mathrm{l}, 10^{-3} \mathrm{~g} / \mathrm{l}$, or $10^{-2} \mathrm{~g} / \mathrm{l}$. a Current $(I)$-voltage $(V)$ relation were constructed by normalizing each $I_{\mathrm{Ca} . \mathrm{T}}$ to that of the maximum inward current with vehicle $\left(I / I_{\text {veh }}\right)$. b Dose-response relationship of tunicamycin on $I_{\mathrm{Ca} . \mathrm{T}}$ was evaluated by a pulse protocol composed of a holding potential of $-100 \mathrm{mV}$ to a test potential for the maximum current $(-30$ or $-25 \mathrm{mV})$ at the stimulation frequency of $0.2 \mathrm{~Hz}$. Data were fitted by the Hill equation yielding $\mathrm{IC}_{50}$ value of $2.01 \times 10^{-3} \mathrm{~g} / \mathrm{l}$. Values represent the mean \pm SE. $* p<0.01$ vs. vehicle

the use-dependent effect of tunicamycin on $\mathrm{Ca}_{\mathrm{V}} 3 \cdot 1-I_{\text {Ca.T }}$, a train of pulses $(0.4 \mathrm{~Hz}, 2.5 \mathrm{~Hz}$ and $4.0 \mathrm{~Hz})$ was applied (Fig. 5a). Repetitive voltage-clamp pulses with or without a treatment of tunicamycin resulted in a negligible changes of $\mathrm{Ca}_{\mathrm{v}} 3 \cdot 1-I_{\text {Ca.T }}$ at the stimulation frequency of $0.4 \mathrm{~Hz}$. At the stimulation ratio of $2.5 \mathrm{~Hz}$, however, $I_{\text {Ca.T }}$ was reduced by $9.2 \%$ without tunicamycin treatment and by $16.9 \%$ with tunicamycin treatment at the second pulse $\left(I_{2} / I_{1}\right)$. At the end of the train pulse (28th pulse), $I_{\mathrm{CaT}}$ ratio $\left(I_{28} / I_{1}\right)$ was reduced to $87.4 \pm 1.1 \%$ without tunicamycin treatment and to $80.0 \pm 1.3 \%$ with tunicamycin treatment. At the stimulation ratio of $4.0 \mathrm{~Hz}, I_{\text {Са.T }}$ was reduced by $16.8 \%$ without tunicamycin treatment and by $39.9 \%$ with tunicamycin treatment at the second pulse $\left(I_{2} / I_{1}\right)$. At the end of the train pulse (28th pulse), $I_{\text {Ca.T }}$ ratio $\left(I_{28} / I_{1}\right)$ was reduced to $70.0 \pm 1.2 \%$ without tunicamycin treatment and to $57.3 \pm 1.5 \%$ with tunicamycin treatment. These results indicate that tunicamycin treatment accelerate the use-dependent reduction of the current particularly at the high stimulation frequency.
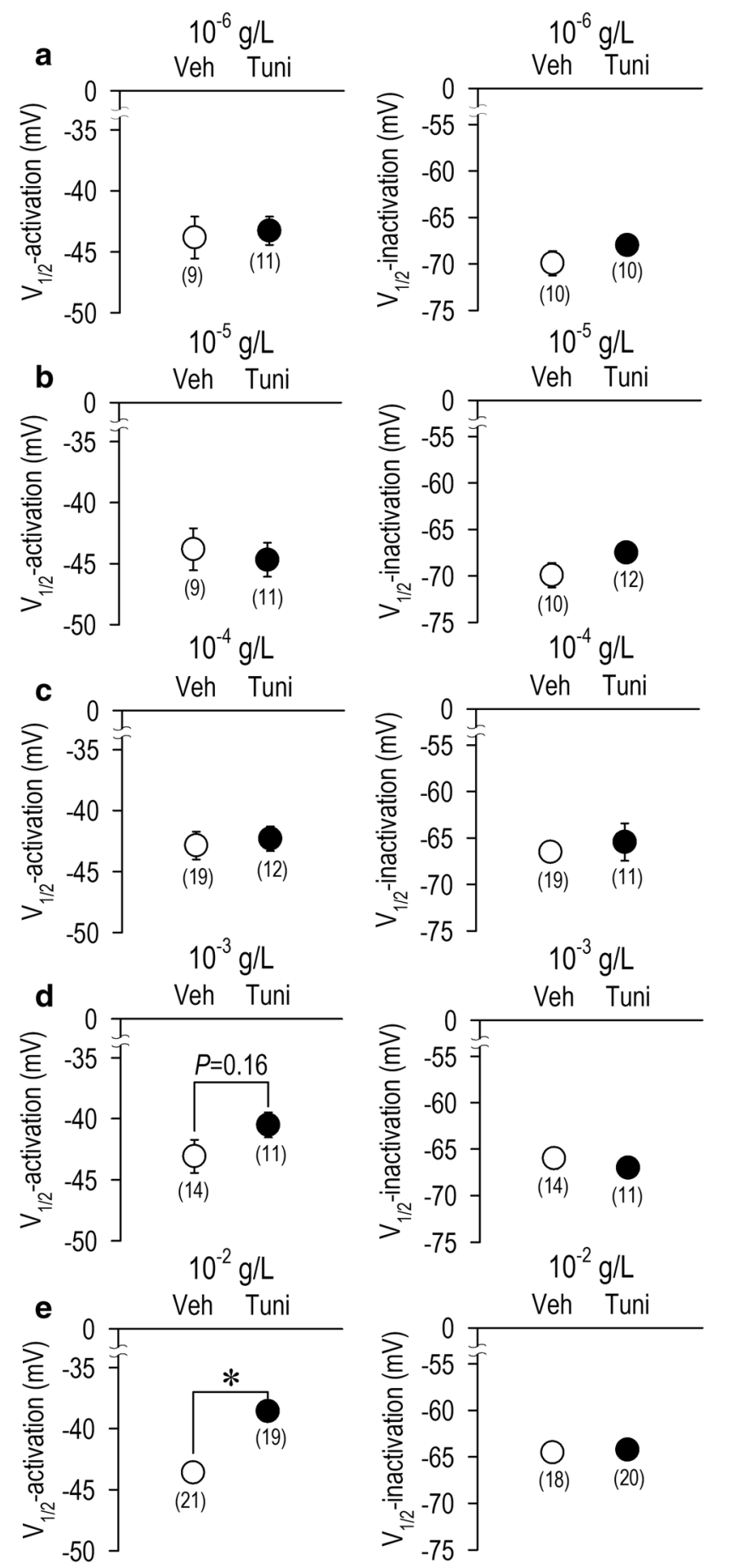

Fig. 4 Concentration-dependent effects of tunicamycin on halfactivation potentials $\left(V_{1 / 2}\right.$-activation) and half-inactivation potentials $\left(V_{1 / 2}\right.$-inactivation). HEK-Ca 3.1 cells were incubated for $24 \mathrm{~h}$ with vehicle or tunicamycin at the concentration of $10^{-6} \mathrm{~g} / 1(\mathbf{a}), 10^{-5} \mathrm{~g} / 1$ (b), $10^{-4} \mathrm{~g} / 1$ (c), $10^{-3} \mathrm{~g} / \mathrm{l}(\mathbf{d})$, or $10^{-2} \mathrm{~g} / \mathrm{l}(\mathbf{e})$. Values for $V_{1 / 2}$-activation and $V_{1 / 2}$-inactivation were obtained by Boltzmann fittings with the same pulse protocol in Fig. 2. The number of cells is indicated in parentheses. Values represent the mean \pm SE. $* p<0.01$ vs. vehicle 


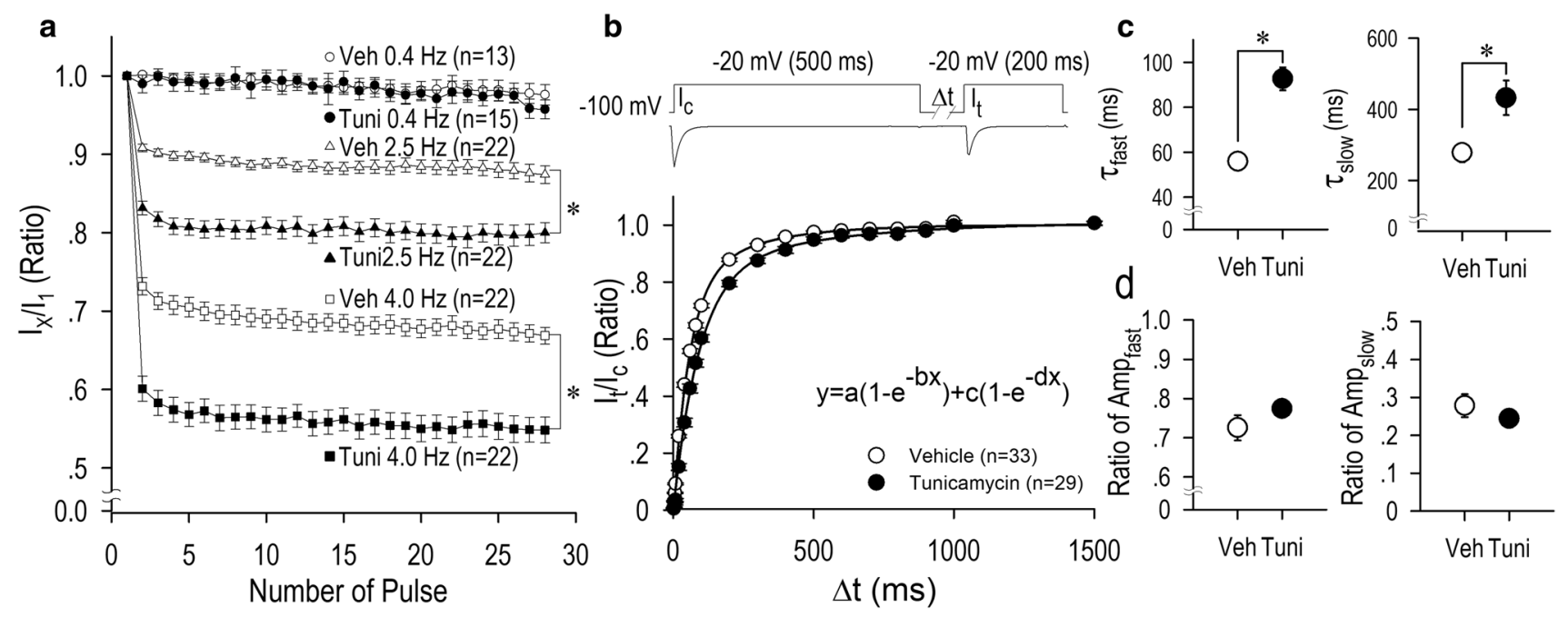

Fig. 5 Use-dependent reduction and recovery from inactivation of $I_{\text {Ca.T }}$ modified by glycosylation inhibition with tunicamycin. a Time course for development of use-dependent reduction of $I_{\text {Сa.T }}$ with or without tunicamycin $\left(10^{-6} \mathrm{~g} / \mathrm{l}\right)$ treatment for $24 \mathrm{~h} . I_{\text {Ca.T }}$ was recorded by a train of 28 pulses consisting of $100-\mathrm{ms}$ duration at a test potential $-10 \mathrm{mV}$ from the holding potential of $-100 \mathrm{mV}$ with the stimulation frequency of $0.4,2.5$, or $4.0 \mathrm{~Hz}$. The current amplitude of the first pulse of train stimulation was assigned as 1.0. b Time course

To further study the effect of tunicamycin treatment on the gating property of the $\mathrm{Ca}_{\mathrm{V}} 3.1$ channel, we examined whether the time of $I_{\mathrm{Ca} . \mathrm{T}}$ recovery from inactivation was modulated by tunicamycin treatment. Thus, we examined the recovery time course from inactivation by using the pulse protocol illustrated in Fig. 5b. Recovery from inactivation was significantly delayed by tunicamycin treatment [fast time constant $\left(T_{\text {fast }}\right)$ : vehicle, $55.9 \pm 2.0 \mathrm{~ms}$; tunicamycin, $92.7 \pm 5.1 \mathrm{~ms}$ ] [slow time constant $\left(T_{\text {slow }}\right)$ : vehicle, $278.1 \pm 26.0 \mathrm{~ms}$; tunicamycin, $432.6 \pm 48.8 \mathrm{~ms}$ ], which is consistent with the findings shown in Fig. 5a, although amplitudes of fast and slow components were substantially unchanged. These results indicate the retarded inactivation process of the channel gating produced by tunicamycin treatment.

\section{Effects of chemical cleavage for removal of glycosylation}

To investigate whether the removal of glycosylation has effects on the channel function when the channel proteins are expressed with the full glycosylation steps on the plasma membrane, we applied a non-specific glycosidase PNGase $\mathrm{F}$ in the cell-culture medium prior to the electrophysiological experiments. $\mathrm{Ca}_{\mathrm{V}} 3 \cdot 1-\mathrm{I}_{\mathrm{Ca} . \mathrm{T}}$ was insensitive to PNGase $\mathrm{F}$ (Fig. 6), suggesting that $N$-glycosylation contributes to the regulation of the gating properties of the channel only when of recovery from inactivation of $I_{\text {Ca.T. }}$ Pulse protocol is shown in the inset. The current amplitude at the conditioning pulse $\left(I_{\mathrm{c}}\right)$ was assigned as 1.0, and the current amplitudes at the test pulse $\left(I_{\mathrm{t}}\right)$ were normalized to the ratio of Ic $\left(I_{t} / I_{\mathrm{c}}\right)$. Curves were fitted to the data using a double-exponential equation shown in the inset. c Time constants for the fast and slow components $\left(T_{\text {fast }}, T_{\text {slow }}\right)$ and $\mathbf{d}$ their amplitudes in equation $\left(\mathrm{Amp}_{\text {fast }}, \mathrm{Amp}_{\text {slow }}\right)$. The number of cells is indicated in parentheses. Values represent the mean \pm SE. $* p<0.01$ vs. vehicle

the channel proteins were processed during the folding and trafficking steps in the cell.

\section{Discussion}

The biosynthesis of $N$-linked glycans needs three steps: (1) synthesis of dolichol-linked precursor oligosaccharide, (2) en bloc transfer of precursor oligosaccharide to protein, and (3) processing of the oligosaccharide [9]. Tunicamycin is widely used as an inhibitor of $N$-linked glycosylation, because tunicamycin inhibits $N$-acetylglucosamine (GlcNAc) phosphotransferase, which catalyzes the transfer of $\mathrm{N}$-acrtylglucosamine-1-phosphase from uridine diphosphate (UDP)-GlcNAc to dolichol phosphate in the first step of glycosylation synthesis [10]. In this regard, it is rightly assumed that tunicamycin triggers a halt of the channel maturation by inhibiting the $N$-linked glycosylation not as a short-term effect but as a long-term effect prior to the trafficking to the plasma membrane. This process probably needs several hours concerning all the synthesis steps of the channel from the gene transcription to the trafficking of proteins to cell surface membrane [8, 9]. In this context, a negligible acute effect of tunicamycin on $\mathrm{Ca}_{\mathrm{V}} 3 \cdot 1-I_{\mathrm{Ca} . \mathrm{T}}$ would be consistent to the postulated function of $\mathrm{N}$-glycosylation to the ion channel. In this study, we have successfully demonstrated that a lack of proper glycosylation not only decreased the channel 

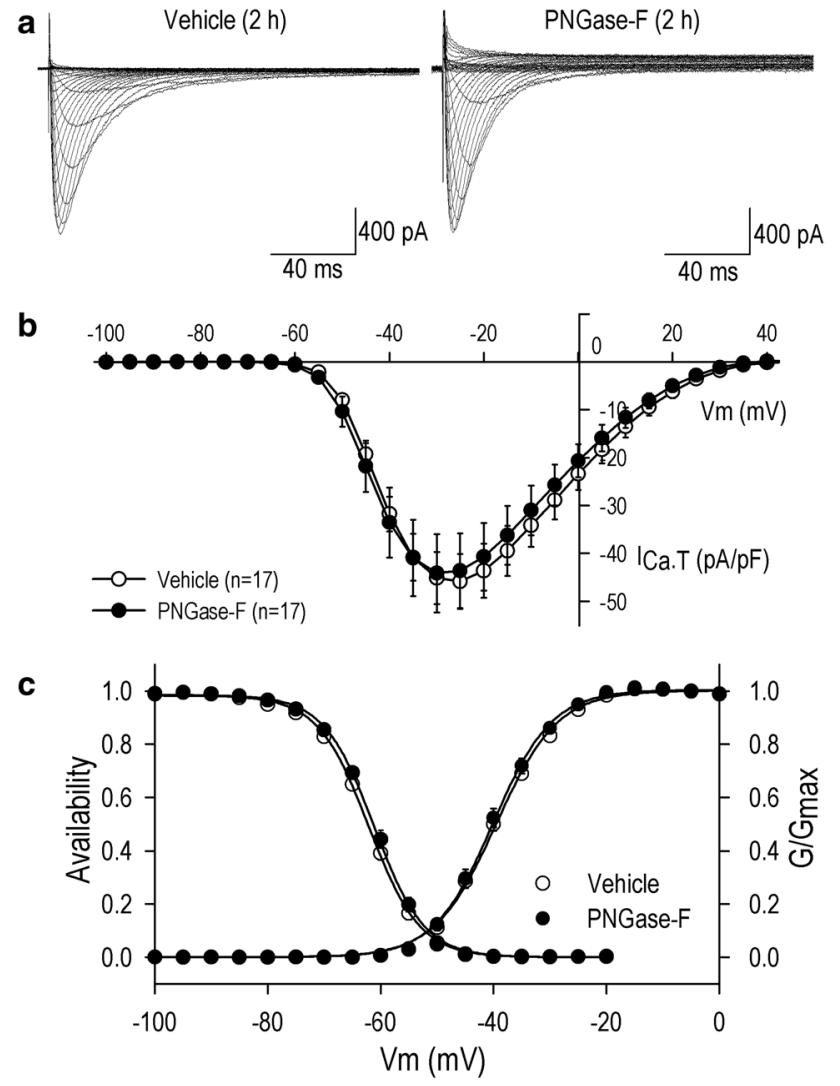

Fig. 6 Effects of chemical cleavage for removal of glycosylation on $\mathrm{Ca}_{\mathrm{V}} 3 \cdot 1-I_{\mathrm{Ca} . \mathrm{T}}$. Changes of the activation $\left(G / G_{\mathrm{max}}\right)$ and the steady-state inactivation (availability) curves were evaluated by a non-specific glycosidase PNGase F in the cell-culture medium prior to the electrophysiological experiments for $2 \mathrm{~h}$. Representative current traces with vehicle or PNGase F (a), group data for current $(I)$-voltage $(V)$ relationship (b), and changes of the activation $\left(G / G_{\max }\right)$ and the steadystate inactivation (Availability) curves as group data (c). The number of cells is indicated in parentheses. Values represent the mean $\pm \mathrm{SE}$

current density but also modified the gating properties of the $\mathrm{Ca}_{\mathrm{V}}$ 3.1-T-type $\mathrm{Ca}^{2+}$ channel.

Although excitation of cardiomyocyte is highly integratively regulated $[6,11-15]$, the trigger of the action potentials mainly depends on the function of voltage-gated ion channels; $\mathrm{Na}^{+}$channels and $\mathrm{Ca}^{2+}$ channels. In many cells, including cardiomyocytes, though, the most important role of $\mathrm{Ca}^{2+}$ channels is to transduce the electrical signals derived from action potentials into the intracellular chemical signals by an increase in $\left[\mathrm{Ca}^{2+}\right]_{\mathrm{i}}$. Two different $\mathrm{Ca}^{2+}$ channels exist in cardiomyocytes; the L-type $\mathrm{Ca}^{2+}$ channels and $\mathrm{T}$-type $\mathrm{Ca}^{2+}$ channels [5]. The current density of the T-type $\mathrm{Ca}^{2+}$ channel $\left(I_{\text {С..T }}\right)$ is relatively low in comparison to those of L-type $\mathrm{Ca}^{2+}$ channel current $\left(I_{\mathrm{Ca} . \mathrm{L}}\right)$ in cardiomyocytes, however $I_{\text {Сa.T }}$ plays important roles in the heart particularly for the pacemaking activity in nodal cells. At generating action potentials, $I_{\text {Ca.T }}$ regulates phase 4 slow diastolic potentials together with currents by $I_{\text {Ca.L }}$, hyperpolarization-activated inward current $\left(I_{\mathrm{f}}\right)$, transient inward current caused by $\mathrm{Na}^{+}-\mathrm{Ca}^{2+}$ exchanger, and others [16]. Regarding the isoform-specific roles of the T-type $\mathrm{Ca}^{2+}$ channel, $\mathrm{Ca}_{\mathrm{V}} 3.1-I_{\text {Ca.T }}$ plays a definite role in the adult heart according to a study with $\mathrm{Ca}_{\mathrm{V}} 3.1(-/-)$ mice; a significantly slow heart rate and a prolonged the sinus node recovery time [17]. On the other hand, $\mathrm{Ca}_{\mathrm{V}} 3.2-I_{\text {Са.T }}$ plays a different role in the heart. Coronary arteries isolated from $\mathrm{Ca}_{\mathrm{v}} 3.2(-/-)$ mice demonstrate reduced relaxation in response to acetylcholine and nitroprusside, which indicates a function of the $\mathrm{Ca}_{\mathrm{V}} 3$.2-T-type $\mathrm{Ca}^{2+}$ channel as essential element for normal relaxation of coronary arteries [18].

Although impacts of glycosylation of the voltage-gated $\mathrm{Ca}^{2+}$ channels have been investigated, it is only lately that the functional significance of $\mathrm{N}$-glycosylation on the function of the T-type $\mathrm{Ca}^{2+}$ channel was investigated. Recent investigations reported potential glycosylation motif within the T-type $\mathrm{Ca}^{2+}$ channels [9]. According to their study, some potential glycosylation sites in the $\mathrm{Ca}_{\mathrm{v}} 3.1-\mathrm{T}$-type $\mathrm{Ca}^{2+}$ channel are conserved, and others are not conserved in the $\mathrm{Ca}_{\mathrm{V}}$ 3.2-T-type $\mathrm{Ca}^{2+}$ channel, which suggests that glycosylation/deglycosylation effects of the $\mathrm{Ca}_{\mathrm{v}} 3.1$ channel and the $\mathrm{Ca}_{\mathrm{v}} 3.2$ channel may not be identical. The role of glycosylation/deglycosylation of the $\mathrm{Ca}_{\mathrm{v}} 3.2$ channel is somewhat controversial among the studies [7, 19-21]. Acute enzymatic deglycosylation of the $\mathrm{Ca}_{\mathrm{v}} 3.2$ channel displayed a reduction of the channel conductance without affecting the voltage dependency of the activation in heterologous expression system with HEK-293 cells [7, 18]. Also ablation of the potential $N$-link glycosylation of the $\mathrm{Ca}_{\mathrm{v}} 3.2$ channel displayed a reduction of the channel conductance and a positive shift in the activation kinetics without affecting the fast inactivation of the channel decay [20]. Unlike the case of the $\mathrm{Ca}_{\mathrm{v}}$ 3.2-channel, potential effect of glycosylation/ deglycosylation on the $\mathrm{Ca}_{\mathrm{V}} 3.1$ channel is largely unknown. In our study, in contrast, elimination of $N$-link glycosylation in the $\mathrm{Ca}_{\mathrm{V}} 3.1-\mathrm{T}$-type $\mathrm{Ca}^{2+}$ channel resulted in a reduction of the maximum conductance, a positive shift in the activation kinetics, and a delayed recovery from the inactivation in a manner consistent with an acceleration of the use-dependent reduction of the current. Given the diversity of the functional results caused by ablations of $N$-linked glycosylation with tunicamycin, it is assumed that multiple $N$-linked glycosylation sites in the $\mathrm{Ca}_{\mathrm{v}} 3.1$ channel distinctly act for the channel maturation prior to the sorting into cell surface plasma membrane. It is also important to note that cleavage of $N$-linked glycosylation by PNGase F, a non-specific enzyme which cleaves $N$-linked glycosylation [22], was without effect on $\mathrm{Ca}_{\mathrm{V}} 3.1-I_{\text {Ca.T }}$ density nor kinetics. These observations support out conclusion that $\mathrm{N}$-glycosylation contributes not only to the cell surface expression of the $\mathrm{Ca}_{\mathrm{v}} 3.1-\mathrm{T}$-type $\mathrm{Ca}^{2+}$ channel but also to the regulation of the gating properties of the channel only when the channel proteins were processed 
during the folding and trafficking steps possibly in the endoplasmic reticulum and in the Golgi by the final settling-down process to the plasma membrane.

Functional abnormalities in $\mathrm{N}$-glycosylation were also observed in other voltage-gated ion channels [23, 24]; modifications differ from channels to channels. For instance, the activation curve and the steady-state inactivation curve of the $\mathrm{Na}_{\mathrm{V}} 1.4$ channel shift toward the depolarization direction when $\mathrm{N}$-glycosylation was blocked by shortage of $\mathrm{N}$-linked sialic acid, although the $\mathrm{Na}_{\mathrm{V}} 1.2, \mathrm{Na}_{\mathrm{V}} 1.5$, and $\mathrm{Na}_{\mathrm{V}} 1.7$ were unaffected [23]. When $\beta$-subunits were simultaneously expressed, activation curves and steady-state inactivation curves of the $\mathrm{Na}_{\mathrm{V}} 1.2, \mathrm{Na}_{\mathrm{V}} 1.5$, and $\mathrm{Na}_{\mathrm{V}} 1.7$ shifted toward the hyperpolarization direction, while both curves shifted toward the depolarization direction in the $\mathrm{Na}_{\mathrm{V}} 1.4$ channel [23]. Meanwhile, ablation of four potential $N$-linked glycosylation sites in the $\mathrm{Ca}_{\mathrm{V}} 1.2$ channel resulted in a decrease in current density and a depolarization shift of the activation curve [24], which suggests a functional similarity with the $\mathrm{Ca}_{\mathrm{v}} 3.1$ channel in this study.

The role of glycosylation in the pathophysiological aspect of ion channel has remained largely overleaped. Defect of glycosylation in the $\mathrm{Ca}_{\mathrm{v}} 3.1$ channel would lead to the pathology of the heart. A reduction of $\mathrm{Ca}_{\mathrm{v}} 3 \cdot 1-I_{\text {Ca.T }}$ would indicate many physiological aberrations in the heart. A reduction of $I_{\text {Ca.T }}$ leads a decrement of window current of T-type calcium channel ( $\left.I_{\text {Ca.T-window }}\right) . I_{\text {Ca.T-window }}$ is the constant inward current providing by the overlap of the activation and the steady-state inactivation near the activation threshold, and is a main way of working for the T-type $\mathrm{Ca}^{2+}$ channel. $I_{\text {Ca.T-window }}$ stands in phase 4 at action potentials in sinus node cells, and could be speculated to facilitate the slow diastolic depolarization of sinus node cells, which contributes to their electrical automaticity [16, 25]. About 20\% of patients with congenital disorders of glycosylation (CDG) have cardiac complications, such as arrhythmias, cardiomyopathies, and structural defects [26]. Patients with CDG-1a who have $\mathrm{N}$-glycosylation defect always have neurological alterations [10]. So, reduction of peak $I_{\mathrm{Cav311- \textrm {T }}}$ and $I_{\mathrm{T} \text {-window }}$ may participate in such CDG symptoms.

In conclusion, we have analyzed the long-term effect of $N$-glycosylation synthesis inhibition on $\mathrm{Ca}_{\mathrm{v}} 3 \cdot 1-I_{\text {С..T. The }}$ inhibition of $\mathrm{N}$-glycosylation synthesis not only decreased the current density of the $\mathrm{Ca}_{\mathrm{v}} 3.1$ channel but also modified the gating kinetics of the channel including a shift of the activation curve to depolarization direction, acceleration of the use-dependent reduction, and slow recovery from inactivation. Although the implication of $N$-linked glycosylation in the $\mathrm{Ca}_{\mathrm{v}} 3.1$ channel is a relatively new notion, emerging evidence indicate that altered glycosylation of the channel proteins may contribute to a number of pathological condition of the heart particularly for arrhythmias and pacemaking abnormalities.
Acknowledgements We are grateful to Ms. Watanabe and Matsuno for their secretary assistance.

\section{Compliance with ethical standards}

Conflict of interest The authors declare no conflicts of interest.

Research involving human participants and/or animals This study does not contain any studies with human participants performed by any of the authors. All procedures performed in studies involving animals were in accordance with the ethical standards of Oita University School of Medicine.

Informed consent Not applicable.

\section{References}

1. Mesirca P, Torrente AG, Mangoni ME (2015) Functional role of voltage gated $\mathrm{Ca}^{2+}$ channels in heart automaticity. Front Physiol 6:19

2. Mesirca P, Torrente AG, Mangoni ME (2014) T-type channels in the sino-atrial and atrioventricular pacemaker mechanism. Pflugers Archy 466:791-799

3. Curran J, Musa H, Kline CF, Makara MA, Little SC et al (2015) Eps15 homology domain-containing protein 3 regulates cardiac T-type $\mathrm{Ca}^{2+}$ channel targeting and function in the atria. $\mathrm{J}$ Biol Chem 290:12210-12221

4. Le Quang K, Benito B, Naud P, Qi X-Y, Shi YF et al (2013) T-type calcium current contributes to escape automaticity and governs the occurrence of lethal arrhythmias following atrioventricular block in mice. Circ Arrhythm Electrophysiol 6:799-808

5. Gillis AM, Russo AM, Ellenbogen KA, Swerdlow CD, Olshansky $B$ et al (2012) HRS/ACCF expert consensus statement on pacemaker device and mode selection. J Am Coll Cardiol 9:1344-1365

6. Jin H, Fujita T, Jin M, Kurotani R, Hidaka Y et al (2018) Epac activation inhibits IL-6-induced cardiac myocyte dysfunction. J Physiol Sci 68:77-87

7. Orestes P, Osuru HP, McIntire WE, Jacus MO, Salajegheh R et al (2013) Reversal of neuropathic pain in diabetes by targeting glycosylation of $\mathrm{Ca}_{\mathrm{V}} 3.2$ T-type calcium channels. Diabetes 62:3828-3838

8. Baycin-Hizal D, Gottschalk A, Jacobson E, Mai S, Wolozny D et al (2014) Physiologic and pathophysiologic consequences of altered sialylation and glycosylation on ion channel function. Biochem Biophys Res Commun 453:243-253

9. Lazniewska J, Weiss N (2017) Glycosylation of voltage-gated calcium channels in health and disease. Biochim Biophys Acta 1859:662-668

10. Aebi M, Hennet T (2001) Congenital disorders of glycosylation: genetic model systems lead the way. Trends Cell Biol 11:136-141

11. Yokoyama U, Ichikawa Y, Minamisawa S, Ishikawa Y (2017) Pathology and molecular mechanisms of coarctation of the aorta and its association with the ductus arteriosus. J Physiol Sci 67:259-270

12. Lee Y, Kwon I, Jang Y, Song W, Cosio-Lima LM et al (2017) Potential signaling pathways of acute endurance exercise-induced cardiac autophagy and mitophagy and its possible role in cardioprotection. J Physiol Sci 67:639-654

13. Khokhlova A, Balakina-Vikulova N, Katsnelson L, Iribe G, Solovyova O (2017) Transmural cellular heterogeneity in myocardial electromechanics. J Physiol Sci 68:387-413 
14. Argenziano M, Tiscornia G, Moretta R, Casal L, Potilinski C et al (2017) Arrhythmogenic effect of androgens on the rat heart. J Physiol Sci 67:217-225

15. Masuda K, Takanari H, Morishima M, Ma F, Wang Y et al (2018) Testosterone-mediated upregulation of delayed rectifier potassium channel in cardiomyocytes causes abbreviation of QT intervals in rats. J Physiol Sci 68:1-9

16. Ono K, Iijima T (2005) Pathophysiological significance of T-type $\mathrm{Ca}^{2+}$ channels: properties and functional roles of T-type $\mathrm{Ca}^{2+}$ channels in cardiac pacemaking. J Pharmacol Sci 99:197-204

17. Mangoni ME, Traboulsie A, Leoni A-L, Couette B, Marger L et al (2006) Bradycardia and slowing of the atrioventricular conduction in mice lacking $\mathrm{Ca}_{\mathrm{V}} 3.1 / \alpha_{1 \mathrm{G}}$ T-type calcium channels. Circ Res 98:1422-1430

18. Chen C-C, Lamping KG, Nuno DW, Barresi R, Prouty SJ et al (2003) Abnormal coronary function in mice deficient in $\alpha 1 \mathrm{H}$ T-type $\mathrm{Ca}^{2+}$ channels. Science 302:1416-1418

19. Weiss N, Black SA, Bladen C, Chen L, Zamponi GW (2013) Surface expression and function of Cav3.2 T-type calcium channels are controlled by asparagine-linked glycosylation. Pflugers Arch 465:1159-1170

20. Lazniewska J, Rzhepetskyy Y, Zhang F-X, Zamponi GW, Weiss $\mathrm{N}$ (2016) Cooperative roles of glucose and asparagine-linked glycosylation in T-type calcium channel expression. Pflugers Arch 468:1837-1851
21. Fukami K, Asano E, Ueda M, Sekiguchi F, Yoshida S et al (2017) High glucose induces $N$-linked glycosylation-mediated functional upregulation and overexpression of $\mathrm{Ca}_{\mathrm{V}} 3.2 \mathrm{~T}$-type calcium channels in neuroendocrine-like differentiated human prostate cancer cells. J Pharmacol Sci 133:57-60

22. Maley F, Trimble RB, Tarentino AL, Plummer TH Jr (1989) Characterization of glycoproteins and their associated oligosaccharides through the use of endoglycosidases. Anal Biochem 180:195-204

23. Johnson D, Montpetit ML, Stocker PJ, Bennett ES (2004) The sialic acid component of the $\beta 1$ subunit modulates voltage-gated sodium channel function. J Biol Chem 279:44303-44310

24. Park H-J, Min S-H, Won Y-J, Lee J-H (2015) Asn-linked glycosylation contributes to surface expression and voltage-dependent gating of $\mathrm{Ca}_{\mathrm{V}} 1.2 \mathrm{Ca}^{2+}$ channel. J Microbiol Biotechnol 25:1371-1379

25. Vassort G, Talavera K, Alvarez JL (2006) Role of T-type $\mathrm{Ca}^{2+}$ channels in the heart. Cell Calcium 40:205-220

26. D'Amico A, Petrini S, Parisi F, Tessa A, Francalanci P et al (2008) Heart transplantation in a child with LGMD2I presenting as isolated dilated cardiomyopathy. Neuromuscul Disord 18:153-155

Publisher's Note Springer Nature remains neutral with regard to jurisdictional claims in published maps and institutional affiliations. 